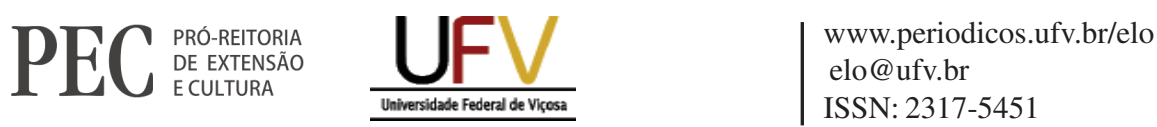

\title{
A educação ambiental em curso formativo: uma proposta para a formação de jovens do ensino médio por meio das artes
}

\author{
Thiago Ezidio de Oliveira ${ }^{1}$, Dayanne da Silva Alves ${ }^{2}$, \\ Lucken Bueno Lucas ${ }^{3}$, Rodrigo de Souza Poletto ${ }^{4}$
}

\begin{abstract}
Resumo: Considerando as macrotendências que se referem aos segmentos da Educação Ambiental, o presente trabalho teve como objetivo desenvolver ações que mitigassem os problemas ambientais. Para o alcance deste objetivo foram utilizadas práticas artísticas e ambientais visando o ensino de Educação Ambiental aos jovens do ensino médio do Colégio Estadual Zulmira Marchesi da Silva na Cidade de Cornélio Procópio-PR no decorrer do ano de 2019. Durante um curso, foram desenvolvidas atividades compostas por práticas a campo estruturadas em conceitos agroflorestais e resíduos sólidos urbanos, mediadas por atividades artísticas, com animações e desenhos de observação (mapeamento ambiental). Os resultados mostraram que abordagens artísticas e práticas ambientais ajudam a promover um processo de sensibilização ambiental por serem integrativas com o meio ambiente, para tanto os cursistas realizaram apontamentos ilustrativos sobre problemas ambientais tendo como destaque resíduos de sólidos urbanos, posteriormente sugeriram a implantação de uma horta em uma área abandonada dentro da Universidade, estes processos contribuíram para que aos alunos adquirissem uma visão consciente dos recursos naturais e preservação do meio ambiente.
\end{abstract}

Palavras-chave: Curso de extensão. Práticas artísticas. Resíduos sólidos urbanos.

Área Temática: Educação Ambiental.

\section{Environmental education in training: a proposal for the formation of high school youth through the arts}

\begin{abstract}
Considering the macro-trends that refer to segments of Environmental Education, this work aimed to develop actions to mitigate environmental problems. To achieve this goal, artistic and environmental practices were used to teach. Environmental education for high school youth from the state school Zulmira Marchesi da Silva in the city of Cornélio Procópio throughout 2019. During a course, activities were developed consisting of field practices structured in agroforestry concepts, urban solid waste mediated by artistic activities, with animations and observation drawings (environmental mapping). The results showed that artistic approaches and environmental practices help to promote a process of environmental awareness because they are integrative with the environment, so the course participants made illustrative notes on environmental problems with the emphasis on urban solid waste, then suggested the implementation of a garden in an abandoned area within the University, these processes contributed to the students acquire a conscious vision of natural resources and preservation of the environment.
\end{abstract}

Keywords: Extension course. Artistic practices. Urban solid waste.

${ }^{1}$ Acadêmico de Ciências Biológicas da Universidade Estadual do Norte do Paraná-UENP, PR Brasil e bolsista do Programa Institucional de Inclusão Social-PIBIS. Endereço: Rodovia PR 160, Km 0, Cornélio Procópio-PR. CEP 86300-000. Telefone: (43) 9613-3797. E-mail: ezidiouenp@gmail.com

${ }^{2}$ Doutoranda do Programa de Pós-Graduação em Ensino de Ciências e Educação Matemática-PECEN na Universidade Estadual de Londrina-UEL e Docente da Faculdade Cristo Rei-FACREI, PR Brasil. Endereço: Rodovia PR160-s/n Conjunto Universitário Cornélio Procópio-PR-CEP 86300-000. Telefone: (43) 9665-7819. E-mail: dayanne_silvaalves@hotmail.com

${ }^{3}$ Docente do Programa de Pós-graduação em Ensino-PPGEN da Universidade Estadual do Norte do Paraná-UENP, PR Brasil. Endereço: Rodovia PR 160, Km 0, Cornélio Procópio-PR. CEP 86300-000. Telefone: (43) 9916-9091.E-mail: luckenlucas@uenp.edu.br

${ }^{4}$ Docente do Programa de Pós-graduação em Ensino-PPGEN da Universidade Estadual do Norte do Paraná-UENP, PR Brasil. Endereço: Rodovia PR 160, Km 0, Cornélio Procópio-PR. CEP 86300-000. Telefone: (43) 9609-7298. E-mail: rodrigopoletto@uenp.edu.br 


\section{La educación ambiental en la formación: una propuesta para la formación de los jóvenes en la escuela secundaria a través de las artes}

Resumen: Considerando las macro-tendencias que se refieren a los segmentos de la Educación Ambiental, este trabajo tuvo como objetivo desarrollar acciones para mitigar los problemas ambientales. Para lograr este objetivo, se utilizaron prácticas artísticas y ambientales para enseñar Educación Ambiental a los estudiantes de secundaria del State College de la ciudad de Cornélio Procópio Paraná a lo largo de 2019. Durante el curso se desarrollaron actividades que consistían en prácticas de campo estructuradas en conceptos de agroforestería, residuos sólidos urbanos mediados por actividades artísticas, con animaciones y dibujos de observación (cartografía ambiental). Los resultados mostraron que los enfoques artísticos y las prácticas ambientales ayudan a promover un proceso de conciencia ambiental al ser integradores con el medio ambiente, por lo que los participantes en el curso hicieron notas ilustrativas sobre los problemas ambientales con énfasis en los desechos sólidos urbanos, y luego sugirieron la implementación de un jardín en un área abandonada dentro de la Universidad, estos procesos contribuyeron a que los estudiantes adquirieran una visión consciente de los recursos naturales y la preservación del medio ambiente.

Palabras clave: Curso de extensión. Prácticas artísticas. Residuos sólidos urbanos.

\section{INTRODUÇÃo}

AEducação Ambiental (EA) objetiva o desenvolvimento de uma compreensão integrada do meio ambiente em suas múltiplas e complexas relações, envolvendo aspectos ecológicos, psicológicos, legais, políticos, sociais, entre outros.

De acordo com Sorrentino et al. (2005), a EA nasce como um processo educativo que conduz a um saber ambiental materializado nos valores éticos e nas regras políticas de convívio social e de mercado, que implica a questão distributiva entre benefícios e prejuízos da apropriação e do uso da natureza.

Podemos considerá-la como a expressão comportamental do indivíduo em relação ao meio em que vive e as ações que realiza em determinado espaço, desencadeando impactos no meio ambiente.

Também é possível compreender a EA a partir de macrotendências, ou seja, grandes movimentos que designam as trajetórias e as mudanças por ela sofridas em contextos sociais e histórico-sociais determinados. Segundo Loureiro (2004) e Loureiro e Trein (2006), os segmentos da EA podem ser concebidos de forma: I) crítica, respaldada no radical questionamento às condicionantes sociais que geram problemas e conflitos ambientais; II) emancipatória, uma vez que visa a autonomia e a liberdade dos agentes sociais ante as relações de expropriação, opressão e dominação; e IIII) transformadora, por visar a mais radical transformação do padrão societário dominante, no qual se define a situação de degradação intensiva da natureza e, em seu interior, da condição humana.

Dentre essas três macrotendências que expressam as diferentes matrizes da EA, optamos por estruturar este trabalho no segmento da Educação Ambiental Crítica, pois Loureiro et al. explicam que

a pedagogia crítica para a Educação Ambiental articula a concepção de educação como processo de educação humana omnilateral com a concepção de ambiente (LOUREIRO et al., 2009, p. 89).

Em síntese, tal pedagogia compromete-se com a formação de sujeitos ambientalmente responsáveis, cujo compromisso social, histórico e político é a construção de sociedades sustentáveis. 
Dessa forma, quando se trabalha com a EA-crítica, é essencial considerar os modelos e as ações sociais que norteiam o agir e o pensar, coletivo e individual, portanto, este processo formativo teve por desafio reestruturar os métodos e estratégias já existentes.

Segundo Dias (2004), o meio ambiente encontra-se em constante mudança em função das alterações de seus componentes bióticos e abióticos, com destaque para as interferências antropogênicas positivas ou negativas.

Nesse sentido, os programas de extensão universitária voltados a EA articulam-se integrando ações como: Cursos, Eventos e Prestação de serviços de objetivo comum, realizados a médio e longo prazo.

Apoiados nos estudos de Mousinho (2003), desenvolvemos uma proposta didática que almejou despertar a consciência para questões relacionadas aos conceitos ambientais, viabilizando o acesso à informação com linguagem adequada e coerente, de modo a contribuir para o desenvolvimento do senso crítico e estimular o enfrentamento das questões ambientais e sociais.

\section{OBJETIVOS}

Nosso trabalho foi inspirado pelos estudos de Mello e Soares (2011), os quais afirmam que técnicas como atividades artísticas, oficinas de desenho, pintura e experiências práticas auxiliam no processo de reconhecimento ativo, conscientização e sensibilização.

A EA se trata de uma perspectiva educacional que permeia as disciplinas que constituem o currículo escolar, permitindo a realização de trabalhos conjuntos entre instituições por meio de ações extensionistas.

O presente trabalho se estabelece como uma sequência de atividades organizadoras de um curso formativo, com interações entre práticas artísticas e ambientais, realizado dentro de um projeto do Programa Institucional de Bolsas de Inclusão Social-PIBIS na Universidade Estadual do Norte do Paraná em parceria com o Colégio Estadual Zulmira Marchesi da Silva na Cidade de Cornélio Procópio-PR no ano de 2019.

O curso teve como objetivo sensibilizar e desenvolver ações para mitigar impactos ambientais gerados por resíduos de sólidos urbanos.

Cabe salientar que a sequência de atividades que foi desenvolvida pode ser trabalhada com alunos da Educação Básica ou como cursos em centros de capacitação ambiental, retiros religiosos, entre outros. A seguir, apresentamos os encaminhamentos metodológicos que estruturam esse curso.

\section{METODOLOGIA}

A presente pesquisa foi desenvolvida a partir da perspectiva qualitativa que, segundo Denzin e Lincoln (2006), a pesquisa qualitativa envolve uma abordagem interpretativa do mundo, o que significa que seus pesquisadores estudam as coisas em seus cenários naturais tentando entender os fenômenos em termos dos significados que as pessoas a eles conferem. 
A utilização dessa metodologia permitiu um detalhamento descritivo de investigações que remetem a hábitos, atitudes e tendências de comportamento do ser humano. Inspirados pela sequência didática de Zabala (1998), inserimos contextualizações artísticas e práticas ambientais, que por meio de diálogos e ações que ocorreram ao longo do curso, buscaram identificar indícios sobre problemáticas ambientais e gerar inferências que fossem capazes de mitigar as ações antrópicas negativas. A seguir, trazemos o Quadro 1 que descreve as características do curso de EA.

Quadro 1 - Caracterização do Curso desenvolvido com alunos do Ensino Médio de uma Colégio Estadual do Paraná.

\begin{tabular}{|l|l|}
\hline Contexto & $\begin{array}{l}\text { Iniciativa suscitada a partir de Programas de Extensão de uma } \\
\text { Universidade Pública do Norte do Paraná. }\end{array}$ \\
\hline Objetivo & $\begin{array}{l}\text { Gerar ações que pudessem mitigar o comportamento antropogênico } \\
\text { negativo por meio de práticas artísticas e ambientais. }\end{array}$ \\
\hline Participantes & Alunos do Ensino Médio de uma Escola Estadual. \\
\hline Pré-Requisitos & $\begin{array}{l}\text { Estar matriculado com devida frequência no Ensino Médio. } \\
\text { Kit multimídia (vídeos e imagens), quadro de Giz, papel mágico, } \\
\text { lápis de cor, sementes, tintas, argila, fichas técnicas, questionários. }\end{array}$ \\
\hline Agentes Formadores & $\begin{array}{l}\text { Os encontros e atividades do curso foram elaborados e conduzidos } \\
\text { por um Docente Orientador, uma estudante de Pós-graduação } \\
\text { (stricto sensu) e um Bolsista (PIBIS) Programa Institucional } \\
\text { de Bolsa de Inclusão Social, de uma Universidade } \\
\text { pública do estado do Paraná. }\end{array}$ \\
\hline
\end{tabular}

Fonte: Dos autores (2020).

Os participantes do curso foram 16 alunos do Ensino Médio de ambos os sexos, com idade entre $13 \mathrm{e}$ 15 anos. Utilizamos 1 (um) questionário de prévio conhecimento com temáticas acerca da EA como resíduos de sólidos urbanos, preservação do meio-ambiente, recursos hídricos e coleta seletiva. 12 (doze) sínteses avaliativas aplicadas uma em cada dia do curso, configurando-se como uma autoavaliação onde o próprio cursista expressa as facilidades e dificuldades de aprendizagem do conteúdo e 1 (um) questionário final. Já as abordagens lúdicas foram compostas por desenhos com base em animações, desenhos de observação (mapeamento), cordéis, esculturas em argila e práticas ambientais.

Cabe salientar que, no início, realizamos uma reunião com os alunos, para a definição do número de encontros, da carga horária estimada e dos dias da semana em que eles poderiam participar. Esse método inicial permitiu que os cursistas escolhessem os dias e horários que lhes fossem melhores, colaborando para que não houvesse futuras desistências.

No Quadro 2, apresentamos a programação definida nessa reunião: 
Quadro 2 - Programação do Curso desenvolvido

\begin{tabular}{|l|l|}
\hline Números de Encontros & Doze encontros \\
\hline Duração horas por Encontro & 2 horas e trinta minutos \\
\hline Dias da semana & Terças e Quintas \\
\hline Local & LIPEBEA- laboratório Interdisciplinar de Pesquisa, \\
& Extensão e Ensino de botânica e Educação Ambiental da \\
& Universidade Estadual do Norte do Paraná-UENP \\
\hline
\end{tabular}

Fonte: Dos autores (2020).

O curso teve como característica primordial iniciar um processo reflexivo sobre EA nos cursistas. Para tanto, foi necessário a observância das ações antrópicas e a realização de questionamentos sociais, tornando possível a reflexão sobre os problemas ambientais, almejando uma ação de inferência para mitigá-los. Segundo Lewin (1978, p. 219), cabe a indagação: "se não é claro onde queremos chegar, como chegaremos lá?" Dessa forma, o curso foi um estudo teórico/prático, que tinha a finalidade de gerar conhecimento e sensibilização e produzir ações quanto à preservação do meio ambiente.

Ao longo dos encontros, foram trabalhadas atividades lúdicas com temáticas ambientais. Utilizamos a metodologia qualitativa para estruturar o corpus dos dados analisados, os quais são compostos pelas representações artísticas que os cursistas realizaram no primeiro encontro. Nesse sentido, a atividade 1 definiu-se como um desenho que objetivou expressar um problema ambiental eminente dentro da sociedade.

O material utilizado para a confecção dos desenhos foi o papel mágico que se caracteriza por ser um papel multicolorido com uma fina camada de tinta preta, desta forma não há necessidade da utilização de lápis colorido para pintar, basta riscá-lo para que as cores se tornem evidentes.

No terceiro encontro, foi aplicada uma atividade intermediária (atividade 3), definida como um mapeamento composto de duas partes: em um primeiro momento, os cursistas escolheram uma área abandonada dentro da universidade e buscaram representá-la da forma como estava, identificando os elementos naturais e não naturais (resíduos sólidos urbanos) presentes no local; posteriormente, na segunda representação, eles retrataram as mudanças físicas que ocorreram no ambiente após a implantação da jardinagem agroflorestal. Tal atividade abrangeu do terceiro até o último encontro, sendo possível caracterizá-la como um manejo ambiental.

Com o objetivo de preservação de identidades e pautados em critérios específicos, foram selecionados 4 (quatro) cursistas que foram codificados com a letra "C" (cursista) e, em seguida, com um número ordinal, ficando $\mathrm{C} 1, \mathrm{C} 2, \mathrm{C} 3, \mathrm{C} 4$, etc. As atividades analisadas, produzidas pelos cursistas, também foram codificadas com a letra "A" (atividade) acompanhada de um número ordinal. Assim, temos A1 para os desenhos realizados no primeiro encontro e A3 para o mapeamento realizado a partir do terceiro encontro até o final do curso. A seguir, apresentamos um quadro que descreve detalhadamente o curso e as atividades que o estruturaram. 


\section{Quadro 3 - Descrição do Curso desenvolvido}

\begin{tabular}{|c|c|c|c|c|}
\hline \multirow[t]{2}{*}{ Encontros } & \multirow[t]{2}{*}{ Temáticas de Ensino } & \multirow{2}{*}{$\begin{array}{c}\text { Descrição das } \\
\text { atividades }\end{array}$} & \multicolumn{2}{|c|}{ Propostas } \\
\hline & & & Modalidade & Instrumentos avaliativos \\
\hline $\mathbf{1}^{\mathbf{0}}$ & $\begin{array}{l}\text { Sólidos urbanos, leis } \\
\text { ambientais, comportamento } \\
\text { do homem no meio ambiente, } \\
\text { ações efetivas para a } \\
\text { preservação da natureza. }\end{array}$ & $\begin{array}{l}\text { (A1) Questionário de } \\
\text { prévio conhecimento (A2) } \\
\text { Desenho em Papel mágico, } \\
\text { com base na animação } \\
\text { criada por Steve Cutts } \\
\text { em Flash e After Effects. }\end{array}$ & $\begin{array}{l}\text { Avaliação } \\
\text { diagnóstica } \\
\text { inicial(AV1) }\end{array}$ & $\begin{array}{l}\text { Desenho em papel } \\
\text { mágico. }\end{array}$ \\
\hline $2^{\mathbf{0}}$ & $\begin{array}{l}\text { Problemas ambientais, } \\
\text { cadeia alimentar, consumo } \\
\text { sustentável hipótese da horta. }\end{array}$ & $\begin{array}{l}\text { (A3) Explicação do desenho (A4) } \\
\text { dinâmica para explicar a cadeia } \\
\text { alimentar. A atividade consistiu } \\
\text { em encenações dos cursistas } \\
\text { representando plantas, antas e onças. }\end{array}$ & $\begin{array}{l}\text { Avaliação } \\
\text { Formativa } \\
\text { (AV2) de acordo } \\
\text { com a temática } \\
\text { de Ensino do } \\
2^{\circ} \text { encontro }\end{array}$ & $\begin{array}{l}\text { Síntese } \\
\text { Avaliativa. }\end{array}$ \\
\hline $3^{\circ}$ & $\begin{array}{l}\text { Observação do meio ambiente } \\
\text { nas dependências do local } \\
\text { onde o curso foi realizado. Foi } \\
\text { escolhida uma área dentro da } \\
\text { Universidade que estava ociosa. }\end{array}$ & $\begin{array}{l}\text { (A5) Consistiu em realizar } \\
\text { um mapeamento desenhando } \\
\text { o ambiente e destacando } \\
\text { resíduos urbanos encontrados } \\
\text { no local. Como parte da } \\
\text { atividade foi realizada } \\
\text { a limpeza do local. }\end{array}$ & $\begin{array}{l}\text { Avaliação } \\
\text { Formativa } \\
\text { (AV3) de acordo } \\
\text { com a temática } \\
\text { de Ensino do } \\
3^{\circ} \text { encontro. }\end{array}$ & $\begin{array}{l}\text { Mapeamento } \\
\text { Síntese Avaliativa. }\end{array}$ \\
\hline $4^{\circ}$ & Ciências ambientais. & $\begin{array}{l}\text { (A6) Aprimoramento } \\
\text { do mapa. }\end{array}$ & $\begin{array}{l}\text { Avaliação Formativa } \\
\text { (AV4) de acordo } \\
\text { com a temática } \\
\text { de Ensino do } \\
4^{\circ} \text { encontro. }\end{array}$ & Síntese Avaliativa. \\
\hline $5^{\circ}$ & $\begin{array}{l}\text { Sistema Agroflorestal, } \\
\text { compostagem, plantio } \\
\text { sem agrotóxicos. }\end{array}$ & $\begin{array}{l}\text { (A7) Registros das } \\
\text { mudanças do local. }\end{array}$ & $\begin{array}{l}\text { Avaliação } \\
\text { Formativa (AV5) } \\
\text { de acordo com a } \\
\text { temática de Ensino } \\
\text { do } 5^{\circ} \text { encontro. }\end{array}$ & SínteseAvaliativa. \\
\hline $6^{0}$ & Ciências Naturais. & $\begin{array}{l}\text { (A8) Bingo com glossário } \\
\text { onde cada número sorteado } \\
\text { possuía uma palavra da } \\
\text { área das ciências biológicas } \\
\text { com sua descrição. }\end{array}$ & $\begin{array}{l}\text { Avaliação } \\
\text { Formativa (AV6) } \\
\text { de acordo com a } \\
\text { temática de Ensino } \\
\text { do } 6^{\circ} \text { encontro. }\end{array}$ & SínteseAvaliativa. \\
\hline $7^{\circ}$ & $\begin{array}{l}\text { Problemas ambientais, } \\
\text { Sólidos urbanos, } \\
\text { Consumo sustentável, } \\
\text { Sist. Agroflorestal, } \\
\text { Compostagem. }\end{array}$ & $\begin{array}{l}\text { Revisão de conteúdos } \\
\text { já abordados. }\end{array}$ & $\begin{array}{l}\text { Avaliação Formativa } \\
\text { (AV7) de acordo com } \\
\text { a temática de Ensino } \\
\text { do } 7^{\circ} \text { encontro. }\end{array}$ & SínteseAvaliativa. \\
\hline $8^{\circ}$ & $\begin{array}{l}\text { Introdução à literatura } \\
\text { de Cordel. }\end{array}$ & $\begin{array}{l}\text { (A9) Apresentação no } \\
\text { Datashow sobre literatura } \\
\text { de cordéis e realização de uma } \\
\text { produção de poesias para compor } \\
\text { as futuras artes dos cordéis. }\end{array}$ & $\begin{array}{l}\text { Avaliação Formativa } \\
\text { (AV8) de acordo com } \\
\text { a temática de Ensino } \\
\text { do } 8^{\circ} \text { encontro. }\end{array}$ & Síntese Avaliativa. \\
\hline $9^{\circ}$ & Conteúdo: Arte de Cordel. & $\begin{array}{l}\text { (A10) Confecção de Cordéis } \\
\text { utilizando isopor, tinta e lápis. }\end{array}$ & $\begin{array}{l}\text { Avaliação Formativa } \\
\text { (AV9) de acordo com } \\
\text { a temática de Ensino } \\
\text { do } 9^{\circ} \text { encontro. }\end{array}$ & $\begin{array}{l}\text { Cordel e Síntese } \\
\text { Avaliativa. }\end{array}$ \\
\hline $10^{\circ}$ & $\begin{array}{l}\text { Conteúdo: Ciências } \\
\text { Ambientais. }\end{array}$ & Limpeza da Horta. & $\begin{array}{l}\text { Avaliação Formativa } \\
\text { de acordo com a } \\
\text { temática de Ensino } \\
\text { do } 10^{\circ} \text { encontro. }\end{array}$ & Síntese Avaliativa. \\
\hline $11^{\circ}$ & Escultura em Argila. & $\begin{array}{l}\text { (A11) Realizar esculturas } \\
\text { em argila utilização a EA } \\
\text { como temática. }\end{array}$ & $\begin{array}{l}\text { Avaliação Formativa } \\
(\text { AV11) de acordo com } \\
\text { a temática de Ensino } \\
\text { do } 11^{\circ} \text { encontro. }\end{array}$ & Síntese Avaliativa. \\
\hline $12^{\circ}$ & $\begin{array}{l}\text { Todos os temas abordados } \\
\text { durante o curso. }\end{array}$ & (A12) Questionário. & $\begin{array}{l}\text { Questionário final. De } \\
\text { acordo com todas as } \\
\text { temáticas trabalhadas } \\
\text { no curso }\end{array}$ & $\begin{array}{l}\text { Síntese Avaliativa } \\
\text { de todo o curso. }\end{array}$ \\
\hline
\end{tabular}




\section{RESULTADOS E DISCUSSÃO}

No primeiro encontro, propusemos aos cursistas uma reflexão sobre os problemas ambientais, para tanto, apresentamos o vídeo "MAN" feito por Steve Cutts em Flash e After Effects no ano de 2012. Com duração de 3 minutos e 36 segundos, o vídeo relata como é o relacionamento do homem com mundo natural e as atitudes que geram adversidades no meio ambiente. Depois, pedimos aos participantes que fizessem desenhos para representar essa reflexão sobre os problemas ambientais. Após a análise dos desenhos, constatamos que tais representações remetiam ao próprio cotidiano dos cursistas, mesmo que ainda estivessem fragmentadas, pois:

Quando desenhamos somos constantemente confrontados com novas e antigas aprendizagens, com novos e antigos conhecimentos. O desenho possibilita, sem hierarquia, organizar esta informação no sentido de tornar visível o que se conhece ou inventa num determinado momento (MARQUES, 2006, p.64).

Essa atividade definiu um panorama dos problemas ambientais, ocasionando indagações pertinentes sobre o tema e fazendo com que os alunos refletissem sobre as ações antropogênicas negativas. Dessa forma, de acordo com Dias (1994), embora as definições de EA sejam muitas e variadas, faz sentido rememorar que todas abrangem a necessidade de considerarmos as questões ambientais de forma integradora.

A seguir, disponibilizamos parte das representações artísticas realizadas pelos cursistas no primeiro encontro, as quais foram selecionadas de acordo com os elementos que refletem os problemas ambientais com maior abrangência, sendo estes eminentes dentro da sociedade.

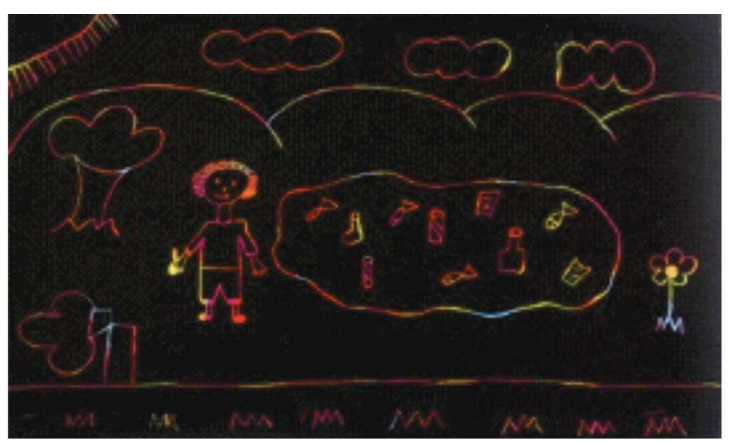

Figura 1-A1-C1

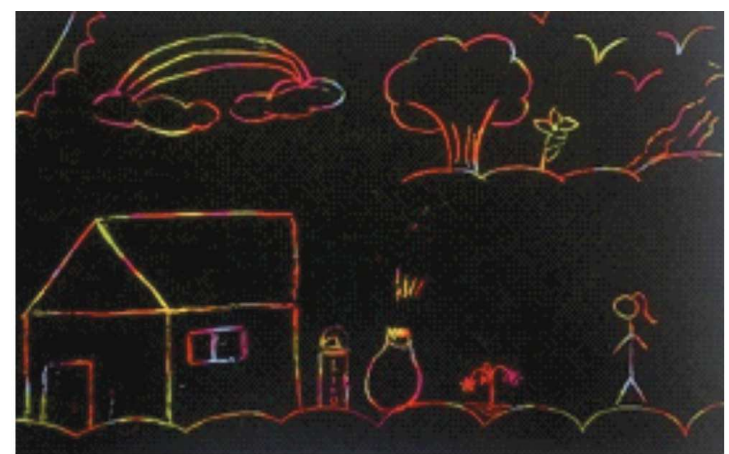

Figura 3-A1-C10

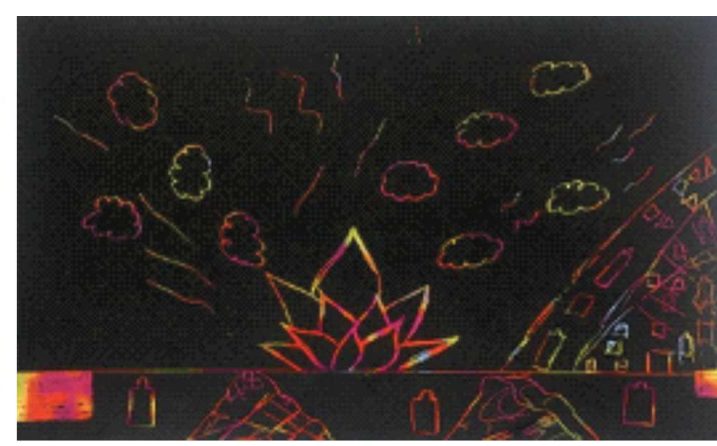

Figura 2-A1-C8

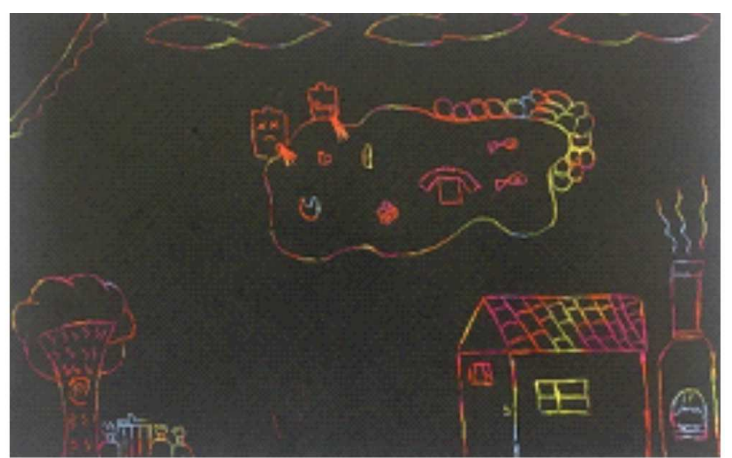

Figura 4-A1-C1

Imagem 1: Representações dos problemas ambientais Fonte: Dos autores (2020). 
Os elementos contidos nos desenhos foram interpretados e distribuídos em um quadro denominado Aspectos geradores (Quadro 4). É evidente que, nesse quadro, estão dispostos os indícios primordiais que causam os problemas ambientais representados pelos cursistas, portanto, podemos observar constantes semelhanças entre os elementos desenhados, por exemplo, a presença do homem no ambiente natural e a presença de resíduos sólidos urbanos poluindo os rios.

As representações continham, ainda, outros elementos que configuraram o acúmulo do lixo doméstico e seu descarte em aterros sanitários, bem como a queima indevida desses materiais:

\begin{abstract}
Quando o lixo é disposto de forma inadequada, em lixões em céu aberto, por exemplo, são inevitáveis problemas sanitários e ambientais. Isso porque estes locais tornam-se propícios para a atração de animais que acabam por se constituírem em vetores de diversas doenças, especialmente para as populações que vivem da catação, uma prática comum nestes locais. Além do mais, são responsáveis pela poluição do ar, quando ocorre a queima dos resíduos, no solo, e das águas, dos lençóis freáticos e superficiais (RIBEIRO; ROOKE, 2010, p.11).
\end{abstract}

A realização dessa atividade permitiu que os cursistas dialogassem sobre os problemas ambientais e se apropriassem de seus aspectos geradores. Foi possível constatar o que eles entendiam sobre a temática dos problemas ambientais, sobre as consequências do descarte de resíduos sólidos urbanos em ambientes naturais e, também, sobre o acúmulo em aterros e no próprio ambiente doméstico. De acordo com De Oliveira et al. (2012, p.90), “o não tratamento e/ou o tratamento inadequado dos grandes volumes de lixo contri-bui para a degradação da biosfera, interferindo na qualidade de vida e na condição ambiental do nosso planeta".

A seguir, disponibilizamos o Quadro 4 que traz a organização dos elementos identificados nos desenhos por categorias.

Quadro 4 - Aspectos geradores indicados pelos cursistas participantes na primeira atividade proposta.

\begin{tabular}{|c|l|l|l|l|}
\hline Cursistas & $\begin{array}{l}\text { 1-Figura Humana/Elementos } \\
\text { naturaise construções }\end{array}$ & $\begin{array}{l}\text { 2-Resíduos de } \\
\text { Sólidos urbanos }\end{array}$ & $\begin{array}{l}\text { 3-Ambiente/ } \\
\text { local }\end{array}$ & $\begin{array}{l}\text { 4-Problema } \\
\text { ambiental }\end{array}$ \\
\hline C1 & $\begin{array}{l}\text { - Figura humana, árvore, } \\
\text { flores, sol, nuvem, lago. }\end{array}$ & $\begin{array}{l}\text { Garrafas, papéis, } \\
\text { plásticos. }\end{array}$ & Ambiente natural. & Poluição do rio. \\
\hline C8 & $\begin{array}{l}\text { - Não representou } \\
\text { Nenhum dos itens definidos. }\end{array}$ & $\begin{array}{l}\text { Resíduos de sólidos } \\
\text { urbanos acumulados } \\
\text { no Ambiente. }\end{array}$ & Aterro sanitário. & $\begin{array}{l}\text { Poluição do meio } \\
\text { ambiente. }\end{array}$ \\
\hline C10 & $\begin{array}{l}\text { - Figura humana, árvore, } \\
\text { flores, sol, nuvem, casa, } \\
\text { pássaros, arco-íris. }\end{array}$ & Lixo doméstico. & Ambiente doméstico. & $\begin{array}{l}\text { Não representou } \\
\text { um problema } \\
\text { ambiental. }\end{array}$ \\
\hline C12 & $\begin{array}{l}\text { - Não representou nenhuma } \\
\text { figura humana, apenas } \\
\text { elementos como: árvores, } \\
\text { sol, nuvem, casa, } \\
\text { churrasqueira, lago. }\end{array}$ & $\begin{array}{l}\text { Garrafas, sacolas } \\
\text { plásticas, roupas e } \\
\text { calçados velhos. }\end{array}$ & $\begin{array}{l}\text { Ambiente doméstico } \\
\text { e natural. }\end{array}$ & Poluição do rio. \\
\end{tabular}

Fonte: Dos autores (2020). 
A análise dos desenhos e sua posterior categorização mostraram o entendimento dos cursistas sobre os problemas ambientais dentro da sociedade. Portanto, os elementos referentes às ações antropogênicas foram representados como precursores do acúmulo e descarte indevido de sólidos urbanos em ambiente doméstico e natural, os quais ocasionam problemas ambientais.

A partir dessa atividade, durante os 2 dias que se seguiram no curso, buscamos levantar hipóteses teóricas de ações que pudessem mitigar o descarte de resíduos sólidos urbanos de forma sustentável. Diante disso, o grupo de alunos sugeriu a implantação de uma horta orgânica sem a utilização de agrotóxicos, de forma que eles escolheriam o que plantar de acordo com o tipo de solo presente no local.

Já no terceiro encontro, foi realizado um mapeamento (atividade 3) para que os cursistas pudessem interagir com maior facilidade com o meio ambiente, retratar suas observações e, posteriormente, reestruturar o local que se assemelha aos apontamentos representados nos desenhos da atividade 1.

O local escolhido foi um ambiente ocioso dentro da Universidade Estadual do Norte do Paraná-UENP na cidade de Cornélio Procópio-PR onde o curso foi realizado. Para tanto, o mapa foi constituído da seguinte maneira: primeiro, os cursistas desenharam o ambiente da forma como o encontrarame, depois, desenharam todas as mudanças que ocorreram ao longo da implantação da horta por meio das técnicas agroflorestais.

De modo geral, as técnicas agroflorestais são sistemas de produção agrícola que combinam espécies arbóreas lenhosas, frutíferas, hortaliças, madeireiras com a possibilidade de serem inseridos animais como, aves, suínos, bovinos e caprinos ao longo do processo.

Essa forma de agricultura sem agrotóxicos como fertilizantes ou pesticidas resgata a importância da preservação ambiental e a utilização dos recursos naturais de forma correta.

Durante a implantação da horta foi realizada a limpeza do local e utilizada a própria vegetação do local para o preparo do solo, foram feitos canteiros onde foram plantadas hortaliças como Almeirão, Nabo, Quiabo, Rúcula, Tomate e Abobrinha. A esse respeito, é possível considerar que:

A implantação de hortas didáticas é uma forma de se trabalhar diversas atividades pedagógicas de Educação Ambiental, sendo um laboratório vivo que auxilia não só no contexto ambiental como no ensino como um todo, sendo uma forma de passar o conhecimento teórico na prática e promover maior integração social (CUNHA et al. 2014, p. 38-48).

Esse processo lhes proporcionou uma reflexão ainda mais abrangente sobre os processos de preservação do meio ambiente, tendo em vista que o local se encontrava abandonado e com inúmeros resíduos de sólidos urbanos provenientes de diversas atividades humanas.

Cabe salientar que, segundo Pimentel et al. (2011), dentre as ações que visam proteger o meio ambiente está a Coleta Seletiva aliada à Educação Ambiental, como ferramenta para mitigar os efeitos dos descartes inadequados dos resíduos. Portanto, a observação dos cursistas em relação aos resíduos produzidos foi complementada pela ação indicada por Pimentel e colaboradores, fazendo com que fossem amenizadas as interferências no meio ambiente. 
Foram exploradas, ainda, ações de sensibilização antes do consumo e o questionamento sobre as necessidades dos indivíduos e os processos pós-consumo, visto que é necessária a separação dos sólidos urbanos de forma correta para que a coleta seletiva tenha eficácia na redução de danos ao ambiente. Pimentel et al. (2011) também definem, de forma sucinta, que uma das ações corretivas é a reciclagem, mas para reciclar, é necessário separar os materiais a partir da coleta seletiva, que é um sistema de recolhimento de materiais recicláveis.

Durante estes diálogos os cursistas foram proativos em realizar apontamentos referentes ao destino dos resíduos sólidos urbanos que sem o gerenciamento correto acabam sendo despejados em áreas de preservação ambiental, rios, oceanos ou locais inapropriados atraindo vetores de doenças.

A lei 12.305/2010 que Institui a Política Nacional de Resíduos Sólidos em seu art. $3^{\circ}$, inciso X, define gerenciamento de resíduos sólidos como:

[...]conjunto de ações exercidas, direta ou indiretamente, nas etapas de coleta, transporte, transbordo, tratamento e destinação final ambientalmente adequada dos resíduos sólidos e disposição final ambientalmente adequada dos rejeitos, de acordo com plano municipal de gestão integrada de resíduos sólidos ou com plano de gerenciamento de resíduos sólidos, exigidos na forma desta Lei (BRASIL, 2010).

Estas ações de gerenciamento dos resíduos sólidos são de extrema importância para a construção de uma sociedade autossustentável com recursos naturais em abundância, que contribuirão para a qualidade de vida das futuras gerações, gerando alternativas que garantem uma vida ecologicamente correta que não agrida o meio ambiente de maneira severa.

Na Imagem 2, observamos que os mapeamentos retratam o ambiente com os elementos supramencionados e, posteriormente, com as mudanças que foram realizadas após a implantação da horta por meio de técnicas agroflorestais.

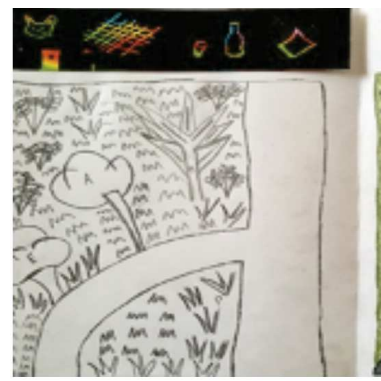

Figura 1-A3 C1

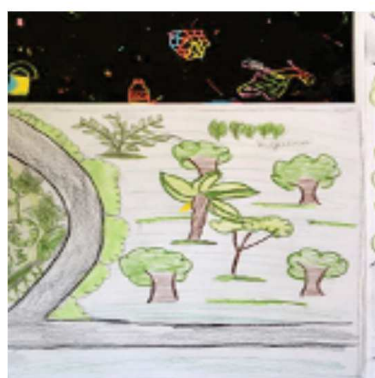

Figura 3-A3 C10
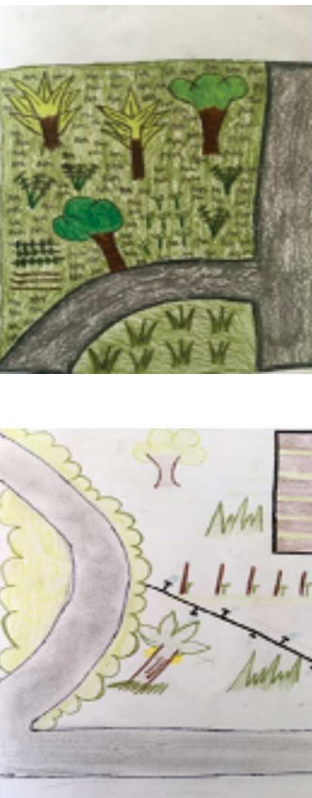

\section{Figura 2-A3 C8}

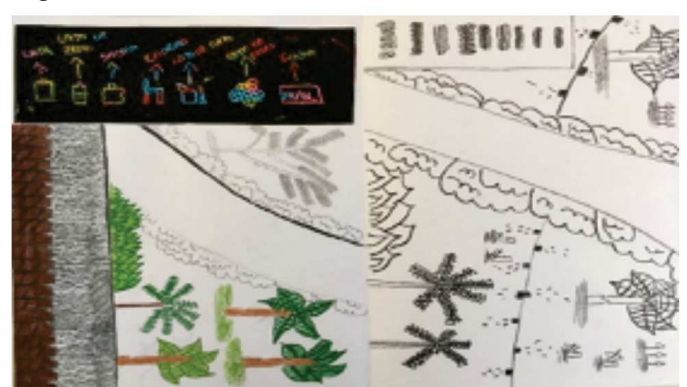

Figura 4-A3 C12

Imagem 2: Mapeamento do local onde os cursistas realizaram a implantação da horta Fonte: Dos autores (2020). 
Após analisarmos os desenhos, organizamos o Quadro 5, constituído por condicionantes que nos fizeram compreender que os cursistas representaram todos os elementos naturais do ambiente e, inclusive, elementos que não faziam parte do meio natural como, por exemplo, resíduos sólidos urbanos (mais especificamente, plásticos). A esse respeito, é possível salientar que:

Em função da sua pouca degradabilidade os plásticos permanecem na natureza por períodos longos, causando a poluição visual e, eventualmente, química do ambiente, para reduzir o impacto dos plásticos no ambiente o gerenciamento dos resíduos torna-se imperativo e, desta forma a estratégia da reciclagem pode ser facilmente introduzida (XAVIER et al., 2006, p.3)

Os sólidos urbanos encontrados pelos alunos dentro do espaço escolhido para representação, demonstram a necessidade da inserção de projetos ambientais educativos dentro da universidade, para que as questões relacionadas ao meio ambiente possam ser tratadas com maior seriedade. Como abordamos anteriormente no Quadro 4, existem aspectos geradores que estão radicados no consumo individual.

Segundo Kremer (2007), os atos de consumir e descartar ocorrem rápida e sucessivamente, pois sempre há algo mais novo, cuja posse, espera-se, finalmente trará a derradeira felicidade e bem-estar prometidos pela propaganda.

Por esse motivo, as contextualizações que englobam os conceitos estruturantes da EA têm por objetivo a elucidação de ações do próprio cotidiano, a fim de rememorar o compromisso individual com o meio ambiente. Nesse sentido:

AEducação Ambiental se concretiza pela adoção de uma abordagem metodológica interdisci-plinar, da complexidade, do conhecimento baseado em valores e práticas sustentáveis, indispensáveis para estimular o interesse e o engajamento de cidadãos e cidadãs na ação e na responsabilidade (JACOBI et al, 2009, p.65-66).

A seguir, disponibilizamos o Quadro 5 (referente à atividade 5), que aborda o que os participantes representaram como elementos naturais e sólidos urbanos encontrados no local durante o preparo do solo para o plantio, bem como as mudanças que ocorreram durante o manejo ambiental realizado e a apresentação de um novo ambiente.

A compreensão que foi adquirida pelos cursistas sobre a EA e sobre as teorias que a constituem como um tema transversal, possibilitou estabelecer relações de práticas artísticas e práticas a campo, permitindo diálogos e reflexões gerando uma percepção aguçada sobre os pequenos detalhes do próprio cotidiano. Todas as atividades do curso foram processos de percepção e expressão estruturadas para uma reeducação ambiental, uma vez que a EA 
Quadro 5 - Atividade de reestruturação do ambiente realizada pelos alunos

\begin{tabular}{|c|c|c|c|c|}
\hline Cursistas & $\begin{array}{l}\text { 1-Observação } \\
\text { do ambiente }\end{array}$ & $\begin{array}{l}\text { 2-O que foi } \\
\text { encontrado? }\end{array}$ & $\begin{array}{l}\text { 3-Mudanças ocorridas } \\
\text { representadas }\end{array}$ & 4-Novo ambiente \\
\hline $\mathrm{C} 1$ & $\begin{array}{l}\text { Representou todos } \\
\text { os elementos } \\
\text { naturais do ambiente. }\end{array}$ & $\begin{array}{l}\text { Sacolas plásticas, } \\
\text { redes de pesca, } \\
\text { garrafas pet, } \\
\text { papeis, latas de } \\
\text { tintas, copos } \\
\text { descartáveis. }\end{array}$ & $\begin{array}{l}\text { Limpeza do local. } \\
\text { Limpeza do local, } \\
\text { plantio de hortaliças, } \\
\text { sistema de irrigação. }\end{array}$ & $\begin{array}{l}\text { Local limpo. } \\
\text { Todas as mudanças } \\
\text { expostas de forma } \\
\text { organizada. }\end{array}$ \\
\hline $\mathrm{C} 8$ & $\begin{array}{l}\text { Representou todos } \\
\text { os elementos naturais } \\
\text { do ambiente. }\end{array}$ & $\begin{array}{l}\text { Lata de tinta, lata } \\
\text { de refrigerante, } \\
\text { sacola plástica, } \\
\text { cadeira velha, rede } \\
\text { de pesca, papéis. }\end{array}$ & & \\
\hline $\mathrm{C} 10$ & $\begin{array}{l}\text { Representou todos } \\
\text { os elementos naturais } \\
\text { do ambiente. }\end{array}$ & $\begin{array}{l}\text { Lata, garrafa, rede, } \\
\text { copo, plástico. }\end{array}$ & $\begin{array}{l}\text { Limpeza do local, } \\
\text { hortaliças em fase } \\
\text { de crescimento, } \\
\text { sistema de irrigação. }\end{array}$ & $\begin{array}{l}\text { Um ambiente limpo, } \\
\text { sem ervas daninhas } \\
\text { e sólidos urbanos. }\end{array}$ \\
\hline $\mathrm{C} 12$ & $\begin{array}{l}\text { Representou todos } \\
\text { os elementos naturais } \\
\text { do ambiente. }\end{array}$ & $\begin{array}{l}\text { Lata, garrafa, rede } \\
\text { de pesca, sacolas } \\
\text { plásticas. }\end{array}$ & $\begin{array}{l}\text { Limpeza do local, } \\
\text { hortaliças em fase } \\
\text { de crescimento. }\end{array}$ & Limpo e organizado. \\
\hline
\end{tabular}

Fonte: Dos autores (2020).

\begin{abstract}
Objetiva promover ambientes educativos de mobilização desses processos de intervenção sobre a realidade e seus problemas socioambientais, para que possamos nestes ambientes superar as armadilhas paradigmáticas e propiciar um processo educativo, em que nesse exercício estejam, os educandos e educadores, nos formando e contribuindo, pelo exercício de uma cidadania ativa, na transformação da grave crise socioambiental que vivenciamos todos (GUIMARÃES, 2004, p.30-31).
\end{abstract}

Considerando que a EA é um tema transversal, tivemos a possibilidade de inserir abordagens artísticas conciliadas com práticas ambientais para que o ensino se tornasse efetivo, possibilitando que os cursistas tomassem conhecimento dos problemas ambientais com maior incidência dentro de seu próprio cotidiano.

Durante a implantação da horta orgânica foram discutidos os impactos ambientais que as embalagens plásticas causam no meio ambiente de modo que foram encontradas em grandes quantidades no local.

Todas as atividades aplicadas no curso foram essenciais para a sensibilização ambiental dos participantes, portanto, toda a ludicidade inserida por meio dos desenhos, práticas e dinâmicas se mostraram eficientes no que diz respeito às questões de ensino, tornando o ambiente agradável para o aprendizado e proporcionando uma experiência memorial que reverbera no cotidiano.

Ações como coleta seletiva, confecção de objetos decorativos com materiais recicláveis, hortas urbanas e compostagem são alternativas para minimizar o descarte incorreto dos sólidos urbanos dentro da sociedade. 


\section{CONCLUSÃO}

As aplicações que foram realizadas durante o curso buscaram consolidar as relações interpessoais, portanto contribuíram para a sensibilização perante o meio ambiente, reforçando questões importantes como o trabalho em equipe.

Com o desenvolvimento deste trabalho, identificamos aspectos geradores de problemas ambientais, os quais nos mostraram explicitamente que a maior dificuldade no que tange ao meio ambiente é a forma inadequada de descarte dos sólidos urbanos.

O processo de industrialização tem ocorrido em larga escala para suprir as demandas de consumo, este rápido avanço influencia as ações antrópicas negativas que impactam o meio-ambiente. Os despejos de resíduos de sólidos urbanos, acúmulo de lixo em locais inapropriados são cada vez mais frequentes devido ao estilo de vida que o capitalismo produz, diante deste cenário, projetos de EA em âmbito extensionista são fundamentais para sensibilizar os modelos de vida estabelecidos dentro da sociedade.

Segundo Barreto (2006), a questão ambiental vem sendo considerada cada vez mais urgente e importante para a sociedade, pois o futuro da humanidade depende da relação estabelecida com a natureza e o uso de seus recursos naturais disponíveis.

Nesse sentido, a utilização de técnicas agroflorestais permitiu a revitalização e a preservação do meio ambiente dentro da própria Universidade em que o curso foi desenvolvido, contribuindo até mesmo para a percepção e sensibilização da comunidade acadêmica (agentes universitários, docentes e discentes).

Podemos afirmar que este curso formou jovens agentes ambientais, capacitados em criar e desenvolver ações em seu cotidiano contribuindo para uma vida sustentável que se preocupa com os impactos ambientais produzidos por suas ações comportamentais.

Desse modo, concluímos que a estratégia geral do curso, pautada na apresentação de problemas ambientais, práticas artísticas, diálogos e práticas a campo gerou resultados positivos, contribuindo para a (re)educação dos cursistas.

Este curso foi uma pequena extensão de nossos anseios sobre o ensino e aprendizagem de EA de modo que contribua para a sensibilização e construção de uma sociedade sustentável estabelecendo uma relação positiva com o meio-ambiente.

Enfim, nossas futuras convicções almejam a elaboração de práticas cada vez mais eficientes mediante a ludicidade para o ensino de EA.

\section{AGRADECIMENTOS}

Este trabalho é resultado de uma extensão Universitária realizada por meio do Programa de Apoio à Inclusão Social (PIBIS) fomentado pela Fundação Araucária portanto; deixamos registrado nossos agradecimentos a estes órgãos de fomento. 


\section{REFERÊNCIAS}

BARRETO, Virginia Paes. AEducação Ambiental como proposta reflexiva da realidade. Monografia (Graduação em Pedagogia) - Centros de estudos gerais aplicados, Universidade Federal Fluminense. Niterói, 2006, p. 75 .

BRASIL, Ministério do Meio Ambiente. Política Nacional de Educação Ambiental - Lei nº 9795/1999, Art $5^{\circ}$ inciso I. Disponível em: <http://www.icmbio.gov.br/educacaoambiental/politicas/pnea.html >. Acesso em: 13 Mai 2019.

CUNHA, Vanessa Tainara et al. Horta na escola: uma forma didática de trabalhar a sustentabilidade. Revista Ibero-americana de Ciências Ambientais, Aquidabã, v. 5, n. 2, p. 38-48, 2014. Disponível em: <https:// doi.org/10.6008/SPC2179-6858.2014.002.0004>. Acesso em: 24 Abr. 2018.

CUTTS, Steve. MAN. 2011 (3m37s). Disponível em: <https://www.youtube.com/ watch?v=WfGMYdalClU\&t=55s $>$. Acesso em: 14 Out. 2019.

DE OLIVEIRA, Luzibênia Leal; DE SOUSA LACERDA, Cícero; DA ROCHA; Joselita Barbosa; SANTOS, Edilene Dias; OLIVEIRA, Sanuyla de Albuquerque; BATISTA, Tatyane Sales de Araújo. Impactos ambientais causados pelas sacolas plásticas: o caso Campina Grande-PB. Revista de Biologia e Farmácia, v. 07, n. 01, p. 88 - 104, 2012.

DENZIN, Norman Kent; LINCOLN, Yvonna Sessions. Introdução: a disciplina e a prática da pesquisa qualitativa. In: DENZIN, Norman Kent; LINCOLN, Yvonna Sessions (Orgs.). O planejamento da pesquisa qualitativa: teorias e abordagens. 2. ed. Porto Alegre: Artmed, 2006. p. 15-41.

DIAS, Genebaldo Freire. Educação Ambiental: princípios e práticas. 2. Ed. São Paulo: Gaia, 1993.

DIAS, Genebaldo Freire. Educação Ambiental: princípios e práticas. 9. Ed. São Paulo: Gaia, 2004.

GUIMARÃES, Mauro. Educação ambiental crítica. In: LAYRARGUES, Philippe Pomier. (coord.). Identidades da educação ambiental brasileira. Brasília: Ministério do Meio Ambiente, 2004.

JACOBI, Pedro Roberto; TRISTÃO, Martha; FRANCO; Maria Isabel Gonçalves Correa. A função social da educação ambiental nas práticas colaborativas: participação e engajamento. Cadernos CEDES, Campinas, v. 29, n. 77, p. 63-79, jan./abr. 2009. Disponível em: <http://www.Cedes.unicamp.br>. Acesso em: 12 Mar. 2020.

KREMER, Joelma. Caminhando rumo ao consumo sustentável: uma investigação sobre a teoria declarada e as práticas das empresas no Brasil e no Reino Unido. 2007. 323 p. Tese (Doutorado em Ciências Sociais) Programa de Estudos Pós-Graduados em Ciências Sociais, Pontifícia Universidade Católica de São Paulo, São Paulo, 2007.

LEWIN, Kurt. Problemas de dinâmica de grupo. São Paulo: Cultrix, 1978.

LOUREIRO, Carlos Frederico Bernardo. Educação Ambiental transformadora. In: LAYRARGUES, Philippe Pomier. (Org.). Identidades da educação ambiental brasileira. Brasília: Ministério do Meio Ambiente, 2004. 
LOUREIRO, Carlos Frederico B. TREIN, Eunice, TOZONI-REIS, Marília Freitas de C; NOVICKI, Victor. Contribuições da teoria marxista para a Educação Ambiental crítica. Cadernos CEDES, Campinas, v. 29, n. 77, p. 81-97, jan./abr. 2009.

LOUREIRO, Carlos Frederico Bernardo; TREIN, Eunice. Educação Ambiental e “Teorias críticas”. In: GUIMARÃES, Mauro (Org.). Caminhos da educação ambiental. Campinas: Papirus, 2006.

MARQUES, Joaquim Jorge Silva. As imagens do desenho: percepção espacial e representação. Faculdade de Belas Artes da Universidade do Porto, 2006.

MELLO, Larissa Evangelista; SOARES, Márlon Herbert. Atividades lúdicas no desenvolvimento da Educação Ambiental. In: II SEAT - Simpósio de Educação Ambiental e Transdisciplinaridade, 2011, Goiânia Anais [...]. Goiânia, UFG, 2011, p.7-11.

MOUSINHO, Poliana Magalhães de Almeida. Glossário. In: Trigueiro, André. (Org.) Meio ambiente no século 21. Rio de Janeiro: Sextante. 2003.

PIMENTEL, Angélica Kelly; ARAUJO, Kássia; Karina. ROCHA, Marcela. Coleta seletiva em uma empresa de limpeza pública de Maceió (AL). Maceió, 2011. Disponível em: <https://www.partes.com.br/ 2011/02/03/coleta-seletiva-em-uma-empresa-de-limpeza-publica-de-maceio-al/> . Acesso em: 18 Mar. 2020

RIBEIRO, Júlia Werneck; ROOKE, Juliana Maria Scoralick. Saneamento básico e sua relação com o meio ambiente e a saúde pública. 2010. Trabalho de Conclusão de Curso (Especialização em Análise Ambiental) Universidade Federal de Juiz de Fora, Minas Gerais, 2010.

SORRENTINO, Marcos; TRAJBER, Rachel; MENDONÇA, Patrícia; JUNIOR FERRARO, Luiz Antônio. Educação ambiental como política pública. Educ. Pesqui., São Paulo, v. 31, n. 2, p. 285-299, ago. 2005. Disponível em: <https://www.scielo.br/scielo.php?pid=S1517-

97022005000200010\&script=sci_arttext\&tlng=pt $>$. Acesso em: 15 Abr. 2019.

XAVIER, Lúcia Helena; CARDOSO, Rosangela; MATOS, Rosa Maria. Legislação ambiental sobre destinação de resíduos sólidos: o caso das embalagens plásticas pós-consumo. In: XIII SIMPEP - Simpósio de Engenharia de Produção, 2006, Bauru. Anais [... ]. Bauru: UNESP, 2006, p.3-10.

ZABALA, Antoni. A prática educativa: como ensinar. Porto Alegre: Artes Médicas, 1998.

Submetido em: 07/11/2020 Aceito em: 02/02/2021. 